\title{
ATUAÇÃO DOS EDUCADORES AMBIENTAIS E A (RE)CONSTRUÇÃO DE SOCIEDADES SUSTENTÁVEIS: CONSTRUCTO DE UMA
TRANSFORMAÇÃO POSSÍVEL
}

\author{
Mônica Andrade Modesto ${ }^{1}$ \\ Tatiana Ferreira dos Santos ${ }^{2}$
}

Resumo: Este escrito busca refletir sobre a atuação dos educadores ambientais na (re)construção de sociedades sustentáveis, necessárias frente aos reflexos da pandemia. As reflexões têm como aporte teórico a tendência crítica da educação ambiental e o pensamento de Pierre Bourdieu. As fontes delineadas dizem respeito a teses e dissertações que foram analisadas à luz da Análise Textual Discursiva e apontaram a necessidade de aprofundamento acerca da discussão sobre o caminho das sociedades sustentáveis no tempo presente e pós-pandêmico.

Palavras-chave: Educadores Ambientais; Sociedades Sustentáveis; Sustentabilidade.

Abstract: This paper seeks to reflect on the acting of environmental educators in the (re) construction of sustainable societies, necessary in view of the effects of the pandemic. The reflections are theoretically based on the critical tendency of environmental education and the thinking of Pierre Bourdieu. The sources outlined refer to theses and dissertations that were analyzed in the light of the Discursive Textual Analysis and pointed out the need to deepen the discussion on the path of sustainable societies in the present and post-pandemic times.

Keywords: Environmental Educators; Sustainable Societies; Sustainability.

1 Universidade Federal de Sergipe. E-mail: monicamodesto1@gmail.com. Link para o Lattes: http://lattes.cnpq.br/7393855479392561

2 Universidade Estadual Paulista. E-mail: tatianaferreira1@yahoo.com.br.

Link para o Lattes: http://lattes.cnpq.br/7764932588183762 


\section{Situando o campo reflexivo}

Nos últimos tempos, especialmente nas últimas três décadas, uma das palavras mais utilizadas pelos povos de norte a sul é sustentabilidade. Tal termo é aplicado a todas as searas que compõem uma sociedade, e, cada vez mais, se observa a popularização de termos que procuram fazer alusão a ela na dimensão socioambiental. No entanto, a ocorrência dessa aplicação conceitual nos variados setores no sistema capitalista ocasiona uma subutilização do sentido e do significado da sustentabilidade que acabam sendo moldados para atender aos interesses do setor que os está utilizando.

Todavia, essa recorrência à sustentabilidade não acontece porque ser sustentável virou modismo. A gênese da questão está para muito além disso: sustentabilidade tornou-se uma questão de vida, uma alternativa para a morte consequente da degradação ambiental que fora provocada ao longo da história do desenvolvimento das sociedades. Mas será que a sustentabilidade tem sido interpretada coerentemente pelas áreas que decidem se apropriar desse conceito?

$\mathrm{Na}$ seara educacional do contexto brasileiro, a ideia de sustentabilidade passa a ser objeto de discussão formal na Educação Básica a partir da publicação dos Parâmetros Curriculares Nacionais, mais especificamente no livro dedicado ao tema transversal Meio Ambiente, em que se aborda o conceito de sustentabilidade como uma transformação social capaz de atenuar a produção de subsistência com foco na exploração da natureza; além disso, tem seu espaço ampliado no currículo por meio da Política Nacional de Educação Ambiental (Lei 9.795/1999) e das Diretrizes Curriculares Nacionais para a Educação Ambiental (Resolução CNE 02/2012), que preconizam a dimensão ambiental da educação e, por conseguinte, a sustentabilidade. Esse último documento, inclusive, avança em direção à transformação dos espaços educacionais em loci que vislumbrem a formação para a construção de sociedades sustentáveis.

Contudo, para que as discussões sobre sustentabilidade e sociedades sustentáveis aconteçam de forma eficaz nos processos formativos, é necessário que nos reconheçamos como educadores ambientais - agentes sociais capazes de assumir o protagonismo no fortalecimento de movimentos contra-hegemônicos que buscam a (re)construção de relações sustentáveis por meio da intencionalidade da práxis - e que os espaços educacionais se assumam como loci promotores de formação ambiental - ambientes formativos que objetivam o desenvolvimento de práxis pedagógicas que abordem a problemática socioambiental de modo transversal, enfatizando a desalienação, a emancipação e a autonomia dos agentes sociais com vistas à ressignificação da tessitura social em direção à sustentabilidade (FREIRE; FIGUEIREDO; GUIMARÃES, 2016).

No período da pandemia da COVID-19 - que tem como desdobramento a ascensão de uma crise complexa que não diz respeito somente à saúde, mas 
à problemática decorrente das implicações econômicas, políticas, sociais, ambientais, psicológicas, culturais e educacionais emergentes da nova organização societária requerida de nós para o combate ao vírus -, torna-se evidente a necessidade de ressignificação de nossas formas de pensar e agir no tempo e no espaço, tencionando, desse modo, a constituição de habitus ressignificados com base nos princípios da sustentabilidade, a fim de assegurar a manutenção da vida humana e o equilíbrio planetário.

Nesse ínterim, o presente escrito tem como objetivo refletir sobre a agência dos educadores ambientais no processo de (re)construção de sociedades sustentáveis no cenário emergente da crise pandêmica. Para tanto, utilizamos os conceitos de campo e de habitus de Pierre Bourdieu $(1983,2005)$ para compreender o modus vivendi e operandi do tecido social e, a partir de então, explicitar como agentes sociais enquanto educadores ambientais podem contribuir para que a dinâmica societária siga na direção da sustentabilidade e, quiçá, de sociedades sustentáveis na conjuntura aventada pela pandemia de COVID-19. Além disso, recorremos à tendência crítica da educação ambiental para compreender o lugar dos educadores ambientais nos processos formativos e na sociedade, bem como para conceber a sustentabilidade e as sociedades sustentáveis epistemológica e praxicamente.

O texto encontra-se dividido em duas partes. Na primeira, discutimos sobre o lugar ocupado pelos educadores ambientais na crise pandêmica, sobre sustentabilidade e sobre as perspectivas para a (re)construção de sociedades sustentáveis. A segunda, por sua vez, traz a apresentação e a discussão dos dados emergentes da análise de teses e dissertações brasileiras que abordam a temática das sociedades sustentáveis e, por fim, apresentamos as possibilidades para novos modos de ser e estar no mundo frente à conjuntura emergente da pandemia vivenciada.

\section{O lugar dos educadores ambientais na crise pandêmica}

Pensar a crise pandêmica emergente do vírus SARS-CoV-2, que tem causado a doença COVID-19, exige uma reflexão sobre a complexidade dimensional dessa crise que não é somente sanitária. Ponderemos que, desde o surgimento das primeiras espécies hominídeas, a relação entre humanos e ambiente é marcada pelo utilitarismo. Com a Revolução Industrial, essa representação antropocêntrica do ambiente passa a ser intensificada, e a natureza passa a ser concebida de maneira cada vez mais recursista, o que reverbera na constituição de modos de ser e estar no mundo limitados ao desenvolvimento econômico, este se constituindo como máxima aventada pelo sistema capitalista.

$\mathrm{Na}$ estrutura desse sistema, os modos de ser e estar no e com o mundo são influenciados pelo consumo e pelo consumismo, acentuados com o advento da globalização. Sob a égide do pensamento de Bourdieu (2005), o mundo é atravessado pelo campo social, um campo de forças no qual os 
agentes sociais ocupam posições de acordo com o capital ${ }^{3}$ que possuem. Das posições ocupadas, cada agente traça estratégias de luta para dominar o campo ou conseguir ocupar outras posições desejadas. Nesse campo, os agentes sociais estão divididos em classes sociais permeadas por relações de dominação e exploração. Dessa maneira, a atuação cotidiana dos agentes sociais, ou seja, seus modos de ser e de estar no e com o mundo, é determinada pelo habitus - um sistema de dispositivos adquiridos por meio da aprendizagem implícita e explícita oriunda da classe da qual emergem -, que funciona como estrutura estruturada do campo social predisposta a funcionar como estrutura estruturante ao tempo em que constitui a regulação das representações e das práticas dos agentes. Contudo, o habitus não é uma estrutura estática e se modifica de acordo com o processo de socialização, tornando-se conformador e reprodutor da ordem dominante à medida que desperta no agente social que está em situação de opressão o desejo de ocupar a posição social ocupada pelo agente opressor (BOURDIEU, 1983).

Sendo a globalização um conceito capitalista intencionalmente pensado para propagar a (pseudo)homogeneização econômica, política e cultural do mundo por meio da aniquilação da identidade dos povos e da alienação ${ }^{4}$ dos agentes sociais (GROPPO, 2005), ela - a globalização - assume no campo o papel de difusora do consumismo como essência do modo de ser e estar capitalista, reverberando na disseminação de uma crise identitária, cultural e civilizatória que repercute no ambiente sob a forma de ações antrópicas degradantes, ocasionando, portanto, uma crise socioambiental.

Em meio a essa crise socioambiental, a saúde, que deveria ser concebida como um elemento essencial da existência humana, assume a condição de mercadoria e, enquanto tal, se torna um fetiche, um produto que tem seu valor assentado na relação com o capitalismo, invisibilizando a relação com o produtor (MARX, 2006; IASI, 2019). Nesse sentido, a saúde humana revela-se fator importante porque permite ao ser valer-se como ser ôntico, capaz de produzir bens e serviços que geram lucro, e não como ser humano em sua dimensão ontológica. O consumismo estimulado pelo sistema capitalista apresenta-se, então, como praxiologia e como regulação do habitus, constituindo, assim, modos de ser e estar no e com o mundo que, em favor do fetichismo da mercadoria, colocam em risco a saúde e o bem-estar dos

\footnotetext{
${ }^{3}$ De acordo com Bourdieu (1983), o capital não se resume à acumulação de propriedades, bens e dinheiro, mas é uma estrutura simbólica e representativa de poder, sendo dividido em três categorias: econômico (detenção de meios e modos de produção e acumulação de bens e valores), social (rede de contatos capazes de serem revertidos em vantagens na sociedade) e cultural (educação, intelecto, vestes, obras de arte, domínio da língua culta, entre outros).

4 Segundo Marx (2006), a alienação consiste na perda da capacidade de percepção da totalidade do processo criativo do trabalho por parte do trabalhador, que, por estar sectarizado na cadeia de produção, não consegue reconhecer-se no produto por ele produzido, tendo solapado, desse modo, o sentimento de unidade e pertencimento ao trabalho - interlocução entre o ser humano e a natureza e categoria fundante da sociedade - e sendo reduzido a um meio do processo produtivo, alienado por não dominar a produção e por não ter consciência da realidade opressora.
} 
agentes sociais, bem como o próprio tecido social, o qual se transfigura em estado de adoecimento.

O cenário brasileiro desvela que o fetichismo da saúde como mercadoria é alçado por meio do governo de ideais neo/ultra/liberais que, a fim de assegurar o Estado mínimo, desmonta o sistema público de saúde, eximindose da responsabilidade pela saúde da população e a transferindo para a sociedade civil, composta por agentes sociais que, em sua maioria, são desprovidos de capital e, sem ter como arcar com os custos da saúde privada, se veem destinados à morte ao serem descartados pelo mercado por estarem impossibilitados de produzir lucro (IASI, 2019). No caso da pandemia de COVID-19, a consequência desse fetichismo, para além dos impactos sociais, econômicos e políticos, é observada no aumento diário de vítimas fatais que, por não fazerem parte da elite econômica, são invisibilizadas e reduzidas a meras estatísticas que desconsideram o valor da vida, que, para o capital, é reificada ${ }^{5}$.

À vista disso, fica evidente que a crise decorrente da pandemia tem proporções muito maiores que a dimensão sanitária, pois traz consigo as implicações de uma tessitura societária marcada por uma estrutura econômica que torna o campo social um espaço de alienação e de reificação dos agentes sociais que, inconscientemente, agem conforme os interesses da ordem dominante (BOURDIEU, 1983, 2005), deixando marcas de degradação no ambiente complexo. Este, por sua vez, tem uma dimensão sistêmica na qual as relações interdependentes entre a espécie humana e os demais seres e entes devem priorizar a superação da injustiça oriunda da supremacia do domínio tecnoeconômico, que é constituído pela cadeia ciência-técnica-indústria-lucro a partir do século XVIII e da colonialidade do poder expressa nas formas de ser e estar no e com o mundo nascidas no eurocentrismo e no antropocentrismo.

Nesse contexto de crise pandêmica e socioambiental, o lugar ocupado no campo social pelos agentes sociais que atuam como educadores ambientais é de enfrentamento e resistência. De acordo com Campos e Cavalari (2017), apesar de professores serem agentes sociais com potencialidade para ocupar a posição de educadores ambientais no campo social, eles não são os únicos aptos para tal, pois, para ser educador ambiental, não é necessário ser licenciado ou exercer a docência, mas se reconhecer como sujeito ecológico frente à sociedade. Segundo Carvalho (2012), um sujeito ecológico é todo aquele capaz de enfrentar a problemática socioambiental agindo como mediador da compreensão de que as relações entre ser humano e ambiente requerem uma transformação de pensamentos, comportamentos e atitudes no sentido de constituírem um conjunto de valores ligados à dimensão ambiental da existência humana que sirva como parâmetro norteador para a construção

5 Em conformidade com Marx (2006), reificação diz respeito à coisificação do trabalho e do trabalhador, que, na sociedade capitalista, são transformados em mercadoria em um processo alienante que torna 0 ser humano em um ser automatizado e passivo frente aos interesses do sistema capitalista. 
de novos modus vivendi e operandi de vida, menos degradantes e mais sustentáveis.

Isto posto, reconhecer-se educador ambiental é um processo complexo, uma vez que, trazendo à baila o pensamento de Bourdieu (1983, 2005), implica o reconhecimento primário de que somos agentes sociais e, nessa condição, seres históricos que ocupam lugares no campo social pré-estabelecidos pela reprodução das estruturas estruturadas e estruturantes que perpetuam o status quo, bem como de que somos dotados da capacidade de agência para ressignificação da posição ocupada e do habitus operado cotidianamente, que, em relação ao ambiente, se constituiu arraigado na representação de mundo antropocêntrica e colonial, geradora da degradação ecossistêmica e da problemática socioambiental, as quais contribuíram para o agravamento da crise pandêmica. Reconhecido esse lugar, implica ainda a percepção de que ser educador ambiental significa um estado de ser e de estar no e com o mundo, haja vista o fato de que se reconhecer como o sujeito ecológico elencado por Carvalho (2012) e por Campos e Cavalari (2017) diz respeito às transformações atitudinais relacionadas ao sentimento de pertencimento ao ambiente, diretamente ligado à nossa consciência existencial.

Desse modo, havendo a ausência desse reconhecimento por parte dos que se denominam ou são denominados educadores ambientais, o que haverá de fato na agência dos sujeitos serão armadilhas paradigmáticas, reforçadoras da ordem dominante e distantes do enfrentamento e da resistência (GUIMARÃES, 2011). Conforme asseveram Freire, Figueiredo e Guimarães (2016, p. 123), a atuação dos educadores ambientais deve ser direcionada para a transformação do mundo e, por conseguinte, para a transformação das relações no mundo: "a realidade hegemônica verticalizada e geradora de situações de opressão, degradação, que, por sua vez, geram a crise socioambiental". Para os autores, o desdobramento dessa transformação será o desenvolvimento de relações dialógicas, que vivenciam o mundo e a vida, pautadas por uma "horizontalidade estruturante como uma nova forma de ser humano nesta vida que estamos vivendo" (FREIRE; FIGUEIREDO; GUIMARÃES, 2016, p. 123).

Uma vez adquirida a consciência do significado do que é ser educador ambiental e percebidos os lugares ocupados por esses agentes sociais e os que são almejados ocupar, a práxis cotidiana, seja ela desenvolvida em ambientes formais ou não, será instrumento de enfrentamento e resistência ao sentido antiecológico dado ao ambiente e à educação ao longo dos tempos, o que tem contribuído para a manutenção da herança do capital à medida que endossa as relações de poder e os jogos políticos em todo o território mundial, ocasionando, assim, a supervalorização da racionalidade econômica (que sacraliza a propriedade privada como bem valioso) em detrimento da racionalidade ambiental (que considera a vida como bem maior), impactando a Terra e a vida de formas catastróficas (LAYRARGUES, 2019). 
O desdobramento da agência dos educadores ambientais é, então, contributo para a (re)construção de um mundo constituído por relações socioambientais pautadas nos princípios da sustentabilidade e por sociedades sustentáveis ou, em conformidade com os teóricos da educação ambiental crítica, um mundo primado por ações contra-hegemônicas e questionadoras do modelo societário imposto pelo capital (FREIRE; FIGUEIREDO; GUIMARÃES, 2016; LAYRARGUES, 2019). Entretanto, o modo como os conceitos de sustentabilidade e de sociedades sustentáveis são apropriados pelas diferentes áreas que compõem a educação e a sociedade brasileiras difere ao tempo em que se conformam com os objetivos delineados pelas classes sociais e, sobremaneira, pelo Estado, que se utiliza do campo educacional para inculcar seus ideais (fundados no capital) no habitus dos agentes sociais. Por isso, reflexionamos sobre esses dois conceitos e suas implicações para a sociedade constituída e para a que desejamos (re)construir.

\section{Afinal, a que nos referimos quando falamos em sustentabilidade e em sociedades sustentáveis?}

O agravamento da questão ambiental nos últimos anos ascendeu o debate em torno de respostas e enfrentamentos que dizem respeito ao futuro do planeta. A questão da sustentabilidade surge como forma de envolver o debate em torno do desenvolvimento aliado à capacidade de satisfazer às necessidades do presente sem comprometer os recursos necessários para as gerações futuras.

Logo, a necessidade de sustentabilidade foi atrelada à ideia de desenvolvimento, e, juntas, foram apresentadas como forma de crescimento econômico aliado à capacidade de repor os recursos naturais, mantendo um equilíbrio entre as finanças, a economia, a natureza e o tecido social. Segundo Silva (2010), essa noção de desenvolvimento sustentável consistiu em uma tentativa de incrementar o discurso ambiental na agenda econômica e social, principalmente após a Conferência de Estocolmo (1972), que, na apresentação do relatório construído pelo Clube de Roma, alertou para a finitude dos recursos não renováveis, como o petróleo, e para a capacidade de produção de alimentos, relacionando a devastação da natureza ao aumento populacional. Como proposta, orientou os países a limitar o crescimento populacional, assim como a estimular o crescimento econômico dos países ditos periféricos.

Nesse sentido, a questão ambiental é apresentada como resultado do aumento populacional, do comportamento das pessoas e da capacidade produtiva dos países, principalmente os de economia dependente. Como resposta, eclodiu a necessidade de processos sustentáveis, principalmente aliados ao desenvolvimento. Conforme destaca Silva (2010), esse aparato ideológico exime as responsabilidades das relações sociais de produção capitalistas, atribuindo a questão ambiental a processos externos, empurrando 
a responsabilidade da degradação global dos recursos naturais para os países mais pobres.

Observamos, assim, que os caminhos da sustentabilidade nascem fincados em uma visão de equilíbrio entre as dimensões econômica e financeira, ecológica e social, mas, apesar de a noção de equilíbrio se apresentar de forma evidente, a noção de sustentabilidade apresenta diferentes perspectivas e visões. Há as dimensões que priorizam os caminhos neoliberais de concentração do mercado econômico, utilizando a "imagem" do ecologicamente correto para atrair consumidores com selos sustentáveis, e persistem os discursos da atribuição da responsabilidade global do aumento populacional em países pobres, sendo atribuída a eles a responsabilidade de sustentabilidade e alinhando a noção de riqueza, consumo e propriedade à noção de equilíbrio e cuidado com a natureza.

Mas, de fato, para onde caminha a sustentabilidade na sociedade do tempo presente? Na sociedade do capital, a sustentabilidade tem sido cooptada para atender aos interesses de mercado e para qualquer manifestação da questão ambiental é apresentado como fator principal o próprio ser humano, com seus valores incoerentes e egoístas, cabendo a ele mesmo estabelecer medidas de como se tornar sustentável, de forma isolada e pontual. Todavia, em uma perspectiva estrutural, adentrando as relações sociais capitalistas, a natureza, dentro desse processo de cooptação, é transformada pelo trabalho humano para a produção de mercadorias, seguindo a marcha de acumulação do capital (TONET, 2015). Esse processo é criado e recriado continuamente, sempre no caminho da acumulação e em busca do lucro, de modo incontrolável. É nesse caminho que, historicamente, os recursos naturais são degradados, assim como a própria vida humana. Em termos estruturais, não há espaço para atender às necessidades humanas, somente à busca pelo lucro. Então, qual o espaço destinado à sustentabilidade nesse processo? Aquele que possa garantir a continuidade do crescimento das forças produtivas do capital ou, em consonância com os pensamentos de Bourdieu (1983), aquele que assegure a reprodução da ordem dominante.

Neste escrito, a perspectiva a que nos referimos é a que questiona a barbárie pregada pelo neoliberalismo, a que questiona as estruturas de reprodução do capital, assim como as suas formas de antagonismos. Ademais, a noção de sustentabilidade que apresente em suas bases a equidade, que não se limite a se amparar nas relações econômicas e financeiras, dialogando com a perspectiva da justiça social e ambiental, e que se proponha a construir outra sociedade essencialmente sustentável, que atenda verdadeiramente às necessidades humanas.

Por conseguinte, essa noção de sustentabilidade atrelada à construção de uma outra sociedade baseada nas necessidades essencialmente humanas e verdadeiramente equitativa está entremeada à noção de sociedades sustentáveis. A necessidade da construção de sociedades sustentáveis ancora-se nos limites da crise ecológica, política, social e econômica 
vivenciada no tempo presente, sobretudo em países de economia dependente, em que a acumulação capitalista se reproduz de forma mais agudizada e violenta. A expropriação histórica dos recursos naturais e da vida vem indicando os caminhos da barbárie da sociedade do capital, em que suas formas de reprodução social colocam em risco a sobrevivência da própria humanidade (MÉSZÁROS, 2011).

Assim, a urgência pela transição para uma sociedade sustentável é real e necessária e diz respeito, sobremaneira, ao rompimento do controle do capital e de todas as suas estruturas arraigadas nos antagonismos e nas contradições. Diz respeito ao futuro da humanidade e da natureza que se encontra nos limites da exploração, da violência, da opressão, da desigualdade, da degradação, do desperdício, frutos do processo de produção e reprodução do capital. Diz respeito à ressignificação do habitus em prol da transformação dessa situação.

Ao longo dos tempos, a noção de sociedade sustentável esteve estritamente ligada à questão da sustentabilidade e do desenvolvimento sustentável. Além disso, é fortemente incorporada à gestão ambiental, em que dimensiona a gestão dos recursos naturais de uma nação, como é apresentado por Diegues (2003) ao atribuir uma sociedade sustentável à capacidade de gerenciamento de recursos de cada nação. Entretanto, essa noção também está ligada à concepção de Chambers (1986 apud DIEGUES, 2003), que define sociedade sustentável como uma forma sustentável do modus vivendi e operandi, corroborando a perspectiva de que essa noção é mais adequada do que a de desenvolvimento sustentável, uma vez que abrange uma maior dimensão no que se refere à capacidade política e social de se desenvolver no ambiente (DIEGUES, 2003).

Em contrapartida, a lógica de responsabilização dos sujeitos pela construção de relações e sociedades sustentáveis envereda para a cooptação desse processo pelas forças do capital, pois, ao tempo em que desvia o cerne da questão para a óptica neoliberal de fragmentação e individualização da sociedade e das relações dos agentes sociais, atua nas relações de mercado a partir da definição de selos verdes e alternativas isoladas, que são vistos como ecologicamente corretos.

Nesse sentido, é preciso apreender discursos defensores de sociedades sustentáveis vindos de diversas direções e com variadas finalidades, a fim de não permitirmos a cooptação dos ideais para serem transformados em instrumentos de reprodução do capital. Desse modo, as sociedades sustentáveis das quais estamos falando - processos de organização social pautados na noção de sustentabilidade aqui defendida - não são uma utopia, mas uma questão necessária frente à situação de crise pandêmica e de decadência das formas de ser e de estar no e com o mundo que supervalorizam o capital econômico e as mercadorias que ele possibilita adquirir e secundarizam o valor da gênese e da essência da existência humana - a vida. 


\section{Representações das sociedades sustentáveis na produção acadêmica brasileira (2015-2020) e proposições para a (re)construção societária}

A fim de refletirmos acerca de como a temática relativa às sociedades sustentáveis tem sido representada na produção acadêmica brasileira e de como contribui de forma praxiológica para a agência social dos educadores ambientais no campo social, analisamos as produções acadêmicas referentes a teses e dissertações produzidas no interstício de 2015 a 2020 que tiveram como escopo discussões relacionadas ao conceito de sociedades sustentáveis. O levantamento das fontes foi realizado na Biblioteca Digital Brasileira de Teses e Dissertações (BDTD), utilizando como palavras-chave para busca as expressões os descritores "Sociedade Sustentável" e "Sociedades Sustentáveis", tendo sido considerados como resultados válidos as teses e dissertações que traziam tais expressões nos campos de cadastro "título" e "assunto" do referido diretório, totalizando, assim, treze trabalhos.

Para tanto, compreendemos como representação a interpretação que os agentes sociais têm do mundo a partir da influência dos habitus constituídos e das concepções circulantes na classe social à qual pertencem e na posição ocupada no campo social (BOURDIEU, 2005). As representações emergentes da análise aqui realizada dizem respeito às interpretações de mundo de agentes sociais que ocupam o campo científico. Assim, questionamos se as representações apresentadas nos discursos dos textos produzidos apresentam consenso com as proposições da literatura e se contribuem para que ultrapassem os muros do campo científico e cheguem até o campo social de forma praxiológica.

Os dados foram analisados à luz da técnica de Análise Textual Discursiva (ATD), que leva em consideração a comunicação expressa ipsis litteris nos documentos elencados como fontes (etapa 01), a desconstrução dos textos presentes nas fontes e seu desdobramento em unidades de sentido, isto é, elementos textuais que designam o sentido e o significado do que foi escrito (etapa 02) e a emergência do novo texto, que é a interpretação da fonte analisada (etapa 03) (MORAES; GALIAZZI, 2013).

O Quadro 1, a seguir, apresenta a síntese conceitual da representação acerca do tema "sociedades sustentáveis" presente nas teses e dissertações analisadas. $O$ item Unidades de Sentido desvela os elementos constituintes das representações que emergiram da análise feita com base nas discussões elencadas anteriormente, tendo o pensamento de Pierre Bourdieu $(1983,2005)$ como eixo norteador da compreensão analítica. 
Quadro 1: Síntese conceitual sobre sociedades sustentáveis em teses e dissertações brasileiras (2015-2020).

\begin{tabular}{|c|c|}
\hline Fonte 01 & $\begin{array}{l}\text { Educação Ambiental dialógico-crítica e sua relação com a prática da agroecologia } \\
\text { e da educação do campo no território do extremo sul da Bahia: entre o } \\
\text { descompasso e o desafio de transformação (PPGAM/Ufscar/Tese/2018) }\end{array}$ \\
\hline $\begin{array}{l}\text { Comunica- } \\
\text { ção textual }\end{array}$ & $\begin{array}{l}\text { "As sociedades ou comunidades sustentáveis relacionam-se com um horizonte } \\
\text { utópico alcançável, movido pela esperança e pelas ações individuais e } \\
\text { coletivas que envolvem elementos culturais e históricos das comunidades na } \\
\text { direção real do bem comum. O caminhar a este horizonte confronta diretamente } \\
\text { as políticas neoliberais porque prioriza a qualidade de vida das sociedades e } \\
\text { o direito de coexistência entre seres humanos e destes com outros seres } \\
\text { bióticos e abióticos. Isto significa pensar outro modelo de desenvolvimento e } \\
\text { de sociedade, que considere, sobretudo, a vida em interação, o manejo } \\
\text { cuidadoso dos bens ambientais, a distribuição equitativa da riqueza gerada } \\
\text { pelo trabalho. Estas e outras práticas são fundamentais para que sociedades } \\
\text { sustentáveis possam de fato se estabelecer dinamicamente (DIEGUES, 2003; } \\
\text { SORRENTINO, 2017)" (p, 26). }\end{array}$ \\
\hline $\begin{array}{l}\text { Unida } \\
\text { sentid }\end{array}$ & $\begin{array}{l}\text { Práxis colaborativa; Enfrentamento aos ideais econômicos neoliberais; Ambiente } \\
\text { complexo; Nova organização social; Sustentabilidade }\end{array}$ \\
\hline Fonte 02 & $\begin{array}{l}\text { A Educação Ambiental nos cursos de licenciatura da } \text { ESALQ/USP } \\
\text { (Esalq/USP/Tese/2018) }\end{array}$ \\
\hline $\begin{array}{l}\text { Com } \\
\text { ção t }\end{array}$ & $\begin{array}{l}\text { "Ao descrever sobre lideranças para uma sociedade sustentável, Ratter (1999) } \\
\text { primeiramente aponta para a contradição existente entre a busca por uma } \\
\text { liderança e a busca por uma sociedade democrática e pluralista. Enquanto a } \\
\text { liderança se referir ao relacionamento líder-seguidor, baseado em uma estrutura } \\
\text { hierárquica e frequentemente autoritária, ela irá se restringir à solução técnica de } \\
\text { problemas, mas não à emancipação humana." (p.316). } \\
\text { "(...) sociedades sustentáveis (consideradas aqui como sociedades justas, } \\
\text { dialógicas e emancipadas)." (p.336). }\end{array}$ \\
\hline US & Sociedade democrática; Pluralidade; Projeto Civilizatório; Emancipação \\
\hline Font & $\begin{array}{l}\text { Educação Ambiental e políticas públicas em Fernando de Noronha: a participação } \\
\text { na construção de escolas e sociedades sustentáveis (Esalq/USP/Tese/2017) }\end{array}$ \\
\hline $\begin{array}{l}\text { Comı } \\
\text { ção t }\end{array}$ & $\begin{array}{l}\text { "A indissociabilidade entre a utopia de sociedades sustentáveis e a ação } \\
\text { educacional ambientalista passa necessariamente pelo planejamento e } \\
\text { construção de políticas públicas com esse foco e compromisso. Políticas } \\
\text { públicas que, acreditando na possibilidade da construção de sociedades } \\
\text { sustentáveis pelas vias democráticas, identifiquem mecanismos que permitam } \\
\text { a expansão radical da democracia, da educação e da participação popular, } \\
\text { como meio e como finalidade, ou seja, como veículos das transformaçóes e } \\
\text { características primeiras das sociedades almejadas. Sociedades sustentáveis, } \\
\text { ambientalistas, democráticas, educadoras e que promovam a participação } \\
\text { de todos e de cada um" (NASCIMENTO; VIANA, } 2007 \text { apud SORRENTINO; } \\
\text { NASCIMENTO, 2010, p. 2019). (p.149). }\end{array}$ \\
\hline US & Democracia; Políticas Públicas; Sustentabilidade; Educação Ambiental \\
\hline Fonte 04 & $\begin{array}{l}\text { Memória e História do Programa USP Recicla: contribuições para a construção de } \\
\text { uma Universidade Sustentável (PPGEO/Unesp/Tese/2016) }\end{array}$ \\
\hline $\begin{array}{l}\text { Comı } \\
\text { ção te }\end{array}$ & $\begin{array}{l}\text { "Falar sobre a construção de sociedades sustentáveis pela via educacional } \\
\text { exige aprofundar-se, simultaneamente, em conhecimentos e propostas de ações } \\
\text { que envolvam a formulação e implantação de políticas públicas e o } \\
\text { aprimoramento dos métodos e técnicas de ensino e aprendizagem que } \\
\text { permitam tais estudos, debates e aprendizados (SORRENTINO; NASCIMENTO, } \\
\text { 2009)" (p. 106). }\end{array}$ \\
\hline US & \\
\hline
\end{tabular}

Continua... 
...continuação.

\begin{tabular}{|c|c|}
\hline Fonte 05 & $\begin{array}{l}\text { nntribuição do Programa Ponte para uma nova universidade: um estudo de } \\
\text { (Esalq/USP/Dissertação/2018). }\end{array}$ \\
\hline $\begin{array}{l}\text { Comunica- } \\
\text { ção textual }\end{array}$ & $\begin{array}{l}\text { "Para formar cidadãos comprometidos com sociedades sustentáveis, é } \\
\text { preciso superar a lógica da modernização conservadora, acusada por Molina } \\
\text { (2016), tanto no campo brasileiro quanto na educação. Ferramentas tecnológicas } \\
\text { não são, por si só, suficientes para resolver a problemática socioambiental. } \\
\text { Tecnologia a serviço de quem? Computadores, laboratórios e recursos } \\
\text { audiovisuais não fazem, por si só, uma boa aula. Transgênicos, pesticidas, } \\
\text { tratores não fazem, por si só, uma boa agricultura. Se os privilégios das classes } \\
\text { dominantes nunca forem questionados, seremos sempre reféns de uma } \\
\text { modernização conservadora" (p. 88). }\end{array}$ \\
\hline US & $\begin{array}{l}\text { Formação; Superação da lógica conservadora do capital; Problemática } \\
\text { socioambiental; Questionamento da ordem hegemônica }\end{array}$ \\
\hline Fonte 06 & $\begin{array}{l}\text { A experiência Educativa na Escola Caminho do Meio e suas Contribuições a uma } \\
\text { Educação e Sociedades Sustentáveis (PPGAMB/Unesc/Dissertação/2017) }\end{array}$ \\
\hline $\begin{array}{l}\text { ica- } \\
\text { tual }\end{array}$ & $\begin{array}{l}\text { "Neste sentido Gadotti afirma que Boff, também coloca que uma sociedade } \\
\text { sustentável seria aquela que é capaz de crescer e atender suas necessidades } \\
\text { sem comprometer a natureza e sem lesar as gerações futuras. Compreender } \\
\text { o planeta como a nossa casa, e a Terra como o nosso endereço comum } \\
\text { enquanto humanidade. Não se pode mais separar as questões sociais das } \\
\text { ambientais. Ainda conforme Boff (1993 apud GADOTTI, 2003, p. 58): "[...] } \\
\text { queremos uma justiça social que combine com a justiça ecológica. Uma não } \\
\text { existe sem a outra." Parece ficar evidente que entre a visão capitalista que impera } \\
\text { em nossa sociedade e a sustentabilidade, existem princípios muito diferentes, } \\
\text { pois como poderia existir uma possibilidade de crescimento sustentável dentro de } \\
\text { um padrão econômico que opera visando sempre o lucro? Que também é regido } \\
\text { pela acumulação de muito por muito poucos? Que preconiza a exploração das } \\
\text { pessoas e do meio ambiente, não levando em consideração suas necessidades? } \\
\text { Numa visão antropocêntrica e de desigualdade social." (p. 72). }\end{array}$ \\
\hline US & Justiça Ambiental; Questão Ambiental; Questão Social; Educação Ambiental \\
\hline Fonte 07 & $\begin{array}{l}\text { A prática pedagógica e a Educação Ambiental na escola pública: um estudo de } \\
\text { caso sobre a possibilidade de construção de uma escola sustentável em } \\
\text { Piracicaba, SP (Esalq/USP/Dissertação/2017) }\end{array}$ \\
\hline ica- & $\begin{array}{l}\text { "De acordo com Brandão (2005) "[...] uma sociedade sustentável é aquela que } \\
\text { busca mudanças e transformações que satisfaçam as verdadeiras vocações } \\
\text { e necessidades dos seres humanos" (BRANDÃO, 2005, p.87). O autor cita } \\
\text { ainda algumas características de uma sociedade sustentável, tais como: a } \\
\text { transformação de mentes e sensibilização de pessoas contra a acumulação } \\
\text { desenfreada de bens e poderes; o direcionamento de nações e povos num } \\
\text { espírito de cooperação para um novo modelo de vida e a oportunidade para } \\
\text { que cada sociedade defina sobre seus rumos." (p. 25) }\end{array}$ \\
\hline US & Cooperação; Satisfação das necessidades humanas; Consciência ecológica \\
\hline Fon & $\begin{array}{l}\text { Educação Ambiental dialógica no assentamento São Gonçalo - Crateús-CE: a } \\
\text { terra como mãe, a ternura no caminhar e novas atitudes no viver } \\
\text { (PPGED/UFC/Dissertação/2017) }\end{array}$ \\
\hline $\begin{array}{l}\text { Comı } \\
\text { ção t }\end{array}$ & $\begin{array}{l}\text { "Os princípios fundantes da Carta da Terra e do Tratado de Educação Ambiental } \\
\text { para as Sociedades Sustentáveis e Responsabilidade Global constituem-se como } \\
\text { fortes instrumentos educativos e no fortalecimento de valores universais pelo } \\
\text { bem comum tão substancial para a valorização da vida." (p.49). }\end{array}$ \\
\hline US & de; Nova rac \\
\hline
\end{tabular}

Continua... 
...continuação.

\begin{tabular}{|c|c|}
\hline Fonte 09 & $\begin{array}{l}\text { Os conceitos de sustentabilidade e de desenvolvimento sustentável na produção } \\
\text { teórica em Educação Ambiental no Brasil: um estudo a partir de teses e } \\
\text { dissertações (PPGED/Unesp/Dissetação/2016) }\end{array}$ \\
\hline $\begin{array}{l}\text { Comunica- } \\
\text { ção textual }\end{array}$ & $\begin{array}{l}\text { "O conceito de sociedades sustentáveis parece ser mais apropriado do que } \\
\text { o de desenvolvimento sustentável. Basicamente, sociedades sustentáveis } \\
\text { refere-se à negação da possibilidade de existir um único modelo ideal de } \\
\text { felicidade e bem-estar a ser alcançado por meio do desenvolvimento" ( } p \text {. } \\
\text { 99). }\end{array}$ \\
\hline US & $\begin{array}{l}\text { Oposição sociedades sustentáveis } \mathrm{x} \text { desenvolvimento sustentável } \\
\text { Arquétipo de felicidade e bem estar }\end{array}$ \\
\hline Fonte 10 & $\begin{array}{l}\text { A transição para sociedades sustentáveis: uma abordagem a partir de } \\
\text { comunidades escolares (Esalq/USP/Dissertação/2016) }\end{array}$ \\
\hline $\begin{array}{l}\text { Comı } \\
\text { ção te }\end{array}$ & $\begin{array}{l}\text { "Uma sociedade sustentável é a que busca mudanças e transformações que } \\
\text { satisfaçam as verdadeiras vocações e necessidades dos seres humanos } \\
\text { (BRANDÃO, 2005, p. 87). Esta é uma proposta realista que determina a } \\
\text { sobrevivência do planeta. Segundo ele, algumas características desse tipo de } \\
\text { sociedade são: 1) a transformação de mentes e sensibilização de pessoas } \\
\text { contra a acumulação desenfreada de bens e poderes; } 2 \text { ) transformar pessoas e } \\
\text { direcionar nações e povos rumo ao espírito de cooperação: socialização da } \\
\text { natureza sustentável e recriadora da vida; } 3 \text { ) proposta de um novo modelo de } \\
\text { vida; 4) abertura para o futuro, para que cada sociedade e geração defina seus } \\
\text { rumos" (p. 52) }\end{array}$ \\
\hline US & $\begin{array}{l}\text { Transformações atitudinais; Humanização; Sustentabilidade; Sensibilização; } \\
\text { Cooperação; Ruptura da ordem dominante; Pluralidade cultural }\end{array}$ \\
\hline Fonte 11 & $\begin{array}{l}\text { Análise da inserção da Educação Ambiental no volume I do currículo do } 6^{\circ} \text { ano } / 5^{\text {a }} \\
\text { série do ensino fundamental do estado de São Paulo } \\
\text { (PPGAM/UFSCar/Dissertacão/2016) }\end{array}$ \\
\hline $\begin{array}{ll}\mathrm{C} \\
\mathrm{C} a \mathrm{c}\end{array}$ & $\begin{array}{l}\text { tureza sistêmica das crises que ameaçam o } \\
\text { elo de civilização dominante como a causa de } \\
\text { obreza e a degradação ambiental" (p. 23). }\end{array}$ \\
\hline US & são sistêmica do ambiente; Problemática socioambiental \\
\hline Fon & $\begin{array}{l}\text { pesina: do diálogo de saberes à semeadura de projetos } \\
\text { unitários (PPGED/UFMT/Dissertação/2016). }\end{array}$ \\
\hline ica- & $\begin{array}{l}\text { "Sociedades Sustentáveis são embasadas na diversidade de buscas e } \\
\text { possibilidades para a construção coletiva das sustentabilidades ambiental, } \\
\text { social, econômica, política e ética. Contrariando o conceito de desenvolvimento } \\
\text { sustentável que, ao nosso ver, se limita apenas à dimensão de crescimento } \\
\text { econômico e sem criticidade" (p. 14). }\end{array}$ \\
\hline US & ; Sustentabilidades \\
\hline Fonte 13 & $\begin{array}{l}\text { A importância da conservação do meio ambiente cultural para a construção de } \\
\text { uma sociedade sustentável: o caso de Laranjeiras/SE } \\
\text { (PRODEMA/UFS/Dissertação/2015) }\end{array}$ \\
\hline $\begin{array}{l}\text { Com } \\
\text { ção t }\end{array}$ & $\begin{array}{l}\text { "O conceito de sociedades sustentáveis é mais adequado do que de } \\
\text { desenvolvimento sustentado, na medida em que possibilita a cada uma delas } \\
\text { definir padrões de produção e consumo, bem como de bem estar a partir de } \\
\text { sua cultura, de seu desenvolvimento histórico e de seu ambiente natural" ( } p \text {. } \\
\text { 22). }\end{array}$ \\
\hline US & \\
\hline
\end{tabular}

Fonte: Biblioteca Digital Brasileira de Teses e Dissertações/IBICT, (2020). 
As noções de sociedade sustentável apresentadas nas dissertações e teses analisadas apontam para perspectivas distintas. Estas se apresentam ora como necessidade de outro modelo de sociedade baseada na equidade, ora como sociedade baseada em valores universais, na cooperação, na democracia, ou mesmo com a superação da lógica conservadora. Apesar da pluralidade de perspectivas compreendidas sob diferentes pontos de vista, ainda é pouco evidente um aprofundamento sobre a natureza dessas sociedades nas fontes elencadas.

Nos trabalhos analisados, são priorizadas as concepções de sociedade sustentável baseadas nas obras de Sorrentino e Nascimento (2010); Diegues (2003); Ratter (1999); Brandão (2005); Gadotti (2003) e na Carta da Terra e no Tratado de Educação Ambiental para as Sociedades Sustentáveis e Responsabilidade Global, sintetizadas no Quadro 2.

Quadro 2: Classificação conceitual sobre sociedades sustentáveis a partir dos autores fundamentados nas dissertações e teses.

\begin{tabular}{|c|c|c|}
\hline Autores e documentos & $\begin{array}{c}\text { Perspectiva sobre } \\
\text { sociedade sustentável }\end{array}$ & $\begin{array}{l}\text { Conceitos classificados a partir } \\
\text { das dissertações e teses }\end{array}$ \\
\hline $\begin{array}{l}\text { Sorrentino e Nascimento } \\
\qquad(2010)\end{array}$ & Democrática & $\begin{array}{l}\text { Outro modelo de sociedade } \\
\text { democrática baseada na } \\
\text { equidade. }\end{array}$ \\
\hline Diegues (2003) & $\begin{array}{l}\text { Novos padrões de } \\
\text { consumo e produção }\end{array}$ & $\begin{array}{l}\text { Novas formas de consumir, } \\
\text { produzir e se relacionar com o } \\
\text { mundo. }\end{array}$ \\
\hline Ratter (1999) & $\begin{array}{l}\text { Liderança, b } \\
\text { ambiente } s\end{array}$ & $\begin{array}{l}\text { Liderança, valores morais e éticos } \\
\text { para construção de um ambiente } \\
\text { saudável. }\end{array}$ \\
\hline Branc & $\begin{array}{l}\text { Atenda às I } \\
\text { hun }\end{array}$ & $\begin{array}{l}\text { As necessidades humanas são } \\
\text { essencialmente alcançadas. }\end{array}$ \\
\hline Gadot & $\begin{array}{l}\text { Ligada ao conceito de } \\
\text { desenvolvimento } \\
\text { sustentável }\end{array}$ & $\begin{array}{l}\text { Construção de valores e habitus } \\
\text { ecológicos e de respeito à } \\
\text { natureza. }\end{array}$ \\
\hline $\begin{array}{l}\text { Carta da Terra e Tratado c } \\
\text { Educação Ambiental para } \\
\text { Sociedades Sustentáveis } \\
\text { Responsabilidade Global }\end{array}$ & Equitativa & $\begin{array}{l}\text { Valores universais e valorização } \\
\text { da vida. }\end{array}$ \\
\hline
\end{tabular}

Fonte: Elaborado à luz das fontes analisadas (2020).

Conforme citam Sorrentino e Nascimento (2010), a concepção de sociedade sustentável pela via dos processos educacionais perpassa a construção de uma sociedade democrática e que necessariamente integraria a formulação de políticas públicas, que envolveriam a construção coletiva na criação de uma outra sociedade ambientalista e democrática. Essa concepção asseverada pelos autores supracitados foi citada em três ${ }^{6}$ das teses analisadas e dispostas no Quadro 1. Ademais, nessa perspectiva de sociedade sustentável, há o direcionamento para uma visão necessária para as relações

\footnotetext{
${ }^{6}$ Fontes 01, 03 e 04 (quadro 01).
} 
humanas e ambientais, mas utópica, uma vez que não destaca como a transformação deve acontecer nas variadas searas do campo social e não se debruça sobre a transformação da agência dos atores sociais que, à luz do pensamento de Bourdieu (1983), ocorreria por meio da ressignificação do habitus.

$\mathrm{Na}$ perspectiva de Diegues (2003), uma sociedade sustentável é construída à medida que cada sociedade define os seus padrões de produção e consumo, considerando o seu desenvolvimento histórico e a sua relação com os recursos naturais. Nessa relação, uma sociedade sustentável, para o referido autor, deixaria de lado os processos industriais, ampliando a noção de sociedade (singular) para sociedades sustentáveis (plurais) com variadas concepções e determinações a partir da cultura de cada uma. Apenas uma ${ }^{7}$ tese abordou tal perspectiva, considerando a necessidade de construir novas formas de consumo e produção, assim como defende o autor mencionado.

O ponto de vista de Ratter (1999) é abordado de forma mais extensa em uma $^{8}$ tese analisada com enfoque central na liderança. Para o autor, é a partir da liderança que é possível construir novos valores baseados no respeito à natureza, tornando possível construir uma nova sociedade sustentável. $\mathrm{Na}$ tese, essa perspectiva é adicionada à óptica de uma sociedade justa, social e ambientalmente, assim como à noção de sociedade sustentável emancipada.

Apesar do anseio por uma sociedade emancipada e justa, a noção de liderança apresentada no trabalho consiste em uma forma de alcançar uma sociedade sustentável. Assim como na visão de Ratter (1999), na tese analisada não são apresentadas mediações necessárias que evidenciem que somente a liderança possibilitaria a criação de uma outra sociedade. Ou seja, não são consideradas as contradições sociais e ambientais que permeiam o tecido social, sobretudo o desemprego, a violência, a pobreza, a fome. Não é possível tornar líderes os agentes sociais de um determinado grupo social mediante o desemprego estrutural, os empregos precários, os direitos trabalhistas ameaçados e fragmentados.

A perspectiva de sociedade sustentável apresentada por Brandão (2005) enfoca a satisfação das necessidades humanas para a construção de um futuro harmonioso com a natureza. Essa noção foi citada em duas ${ }^{9}$ dissertações analisadas, destacando principalmente a compreensão de uma sociedade sustentável baseada na satisfação das necessidades do presente sem comprometer as gerações futuras.

Segundo Gadotti (2003), a noção de sociedade sustentável é a mesma do desenvolvimento sustentável. Apesar de esse autor apresentar uma diversidade de compreensões, mantém a necessidade de criar uma sociedade que atenda às necessidades das gerações presentes sem comprometer os

\footnotetext{
${ }^{7}$ Fonte 01 (quadro 01).

${ }^{8}$ Fonte 02 (quadro 01).

${ }^{9}$ Fontes 07 e 10 (quadro 01).

Revbea, São Paulo, V. 15, № 4: 528-548, 2020.
} 
recursos das gerações futuras. Para ele, é preciso compreender a questão ambiental interligada à questão social, assim como questionar as formas de produzir socialmente. Apenas uma ${ }^{10}$ dissertação analisada está atrelada a essa perspectiva, apresentando uma visão que se coaduna em parte com o pensamento de Gadotti (2003) e em parte com a perspectiva apresentada por Brandão (2005).

O Tratado de Educação Ambiental para Sociedades Sustentáveis e Responsabilidade Global, apresentado durante a Eco 92, dispõe de reflexões que envolvem a necessidade de uma educação ambiental crítica para a construção de sociedades sustentáveis. Apenas uma ${ }^{11}$ dissertação enfocou a concepção de sociedade sustentável baseada no Tratado de Educação Ambiental para Sociedades Sustentáveis e Responsabilidade Global. No tratado, a educação ambiental crítica é apresentada como processo fundamental na transformação da atual sociedade e na construção de valores para se alcançar um "desenvolvimento harmonioso" com a natureza e com as pessoas. Entretanto, no documento, não é apresentada de forma evidente a natureza dessa sociedade sustentável, mas, sim, a necessidade de sociedades sustentáveis, no plural.

A pluralidade é imprescindível nos processos emancipatórios, principalmente em se tratando da transição de uma realidade social e econômica para uma nova relação social baseada na equidade. Mas é preciso situar que, assim como a noção de sustentabilidade apresenta diferentes perspectivas e ópticas, cooptadas por diferentes setores da sociedade e adaptadas a diferentes ideologias, a noção de sociedade sustentável pode abarcar as intencionalidades ideológicas de uma sociedade neoliberal, por exemplo.

Outro ponto evidente no Tratado de Educação Ambiental para Sociedades Sustentáveis consiste na centralidade da educação ambiental como principal processo na construção de uma sociedade sustentável. É preciso destacar a importância da educação ambiental crítica transformadora, mas atrelada ao trabalho, à cultura, à ética, à educação, em uma dimensão de totalidade que contemple as variadas extensões da vida humana. Segundo Layrargues (2011), o trabalho, juntamente com a cultura, compõe um "diálogo entre o plano material e o plano simbólico quanto aos determinantes da crise ambiental, rompendo assim a perspectiva reducionista que minimiza a importância da base material da crise ambiental" (LAYRARGUES, 2011, p. 79).

Apreender as dimensões culturais, éticas e do trabalho consiste em analisar os seres humanos em sociedade, na sua complexidade, integrantes das relações sociais de produção. De tal modo, significa apreender a questão ambiental como uma das expressões da questão social, fruto da contradição fundamental entre capital e trabalho. É entender as determinações

\footnotetext{
${ }^{10}$ Fonte 06 (quadro 01).
}

${ }^{11}$ Fonte 08 (quadro 01). 
totalizadoras do controle do capital (MÉSZÁROS, 2011) nas variadas dimensões da vida, seja na saúde, na agricultura, na educação, na política ou na arte.

Sendo assim, a pluralidade pertinente e necessária para a construção de sociedades sustentáveis deve apresentar como base o diálogo entre saberes (LEFF, 2014), como também as intencionalidades ideológicas, e partir da vida humana em sociedade para a vida humana em uma nova sociedade, essencialmente equitativa e com uma nova relação entre os próprios seres humanos e com a natureza, na qual não há hierarquização entre as espécies e formas de vida nem representação do mundo fundada no antropocentrismo.

Há uma evidente necessidade apresentada em dois trabalhos de desmistificar a diferença entre sociedades sustentáveis e desenvolvimento sustentável, no entanto ainda é possível compreender o sentido de sociedade sustentável arraigado no de desenvolvimento sustentável, mesmo quando colocados em lados opostos. Tal perspectiva ainda destaca a necessidade de trocar a noção de desenvolvimento sustentável pela de sociedades sustentáveis, mas não há uma explicação coerente que apresente as descrições ou compreensões sobre a sociedade sustentável referida em alguns trabalhos. Essa perspectiva é trabalhada em duas ${ }^{12}$ dissertações analisadas.

Desse modo, a partir dos elementos emergentes das representações apresentadas nas fontes analisadas, é possível verificar que o tema sociedades sustentáveis é abordado na produção acadêmica brasileira em consenso com as proposições presentes na literatura especializada, porém de forma lacunar, na medida em que não há aprofundamento conceitual nem apresentação e/ou encaminhamentos dos meios pelos quais possa ocorrer a transição das sociedades consumistas para as sustentáveis.

Remetendo essa análise ao pensamento de Pierre Bourdieu (1983, 2005), que tenciona a reflexão de que as estruturas, representações e práticas sociais, ao tempo em que se constituem como estruturas estruturadas da realidade, são, continuamente, constituídas como estruturas estruturantes, frutos das condições de produção e perpassadas por mecanismos de dominação que influenciam a articulação social materializada pelos agentes sociais, compreendemos que a proposição de sociedades sustentáveis é possível de ser efetivada à medida que houver no campo social uma dinâmica de lutas e embates que objetivem a ruptura da reprodução do status quo. Para tanto, é mister que os agentes sociais se reconheçam como partícipes da sociedade e das lutas sociais para que se mobilizem atitudinalmente no cotidiano do campo social, ocupando as posições sociais de educadores ambientais.

Assim, a atuação dos agentes sociais enquanto educadores ambientais torna-se elemento fulcral para o enfrentamento (a curto e longo prazo) ao

${ }^{12}$ Fontes 09 e 13 (quadro 01).

Revbea, São Paulo, V. 15, № 4: 528-548, 2020. 
habitus consumista engendrado nas formas de ser e estar no mundo fomentadas pelo sistema capitalista. Porém, é preciso destacar que tal atuação não incide na responsabilização individual dos sujeitos, pois o processo de enfrentamento é colaborativo, só sendo fecundo mediante a percepção de que a coletividade no campo social se faz necessária diante das lutas cotidianas.

À vista disso, é emergente a proposição de que a transição para as sociedades sustentáveis é um processo dinâmico de luta contínua inscrito no campo social em que os agentes sociais, na posição de educadores ambientais, mobilizados por habitus ressignificados, podem mobilizar a ressignificação das representações de mundo para outrem por meio de estratégias de combate que vislumbram e propiciam a reconstrução da tessitura do campo social na direção da modificação das estruturas estruturadas e estruturantes das relações sociais que são os pilares que sustentam o modo consumista de ser e estar no e com o mundo em direção a representações e práticas sociais voltadas para a sustentabilidade, culminando na materialização de relações e ações ressignificadas, com vistas à (re)construção de um estruturalismo societário que tem como fundante a valorização da vida. O esquema representativo disposto na Figura 1, na sequência, exemplifica esse processo.

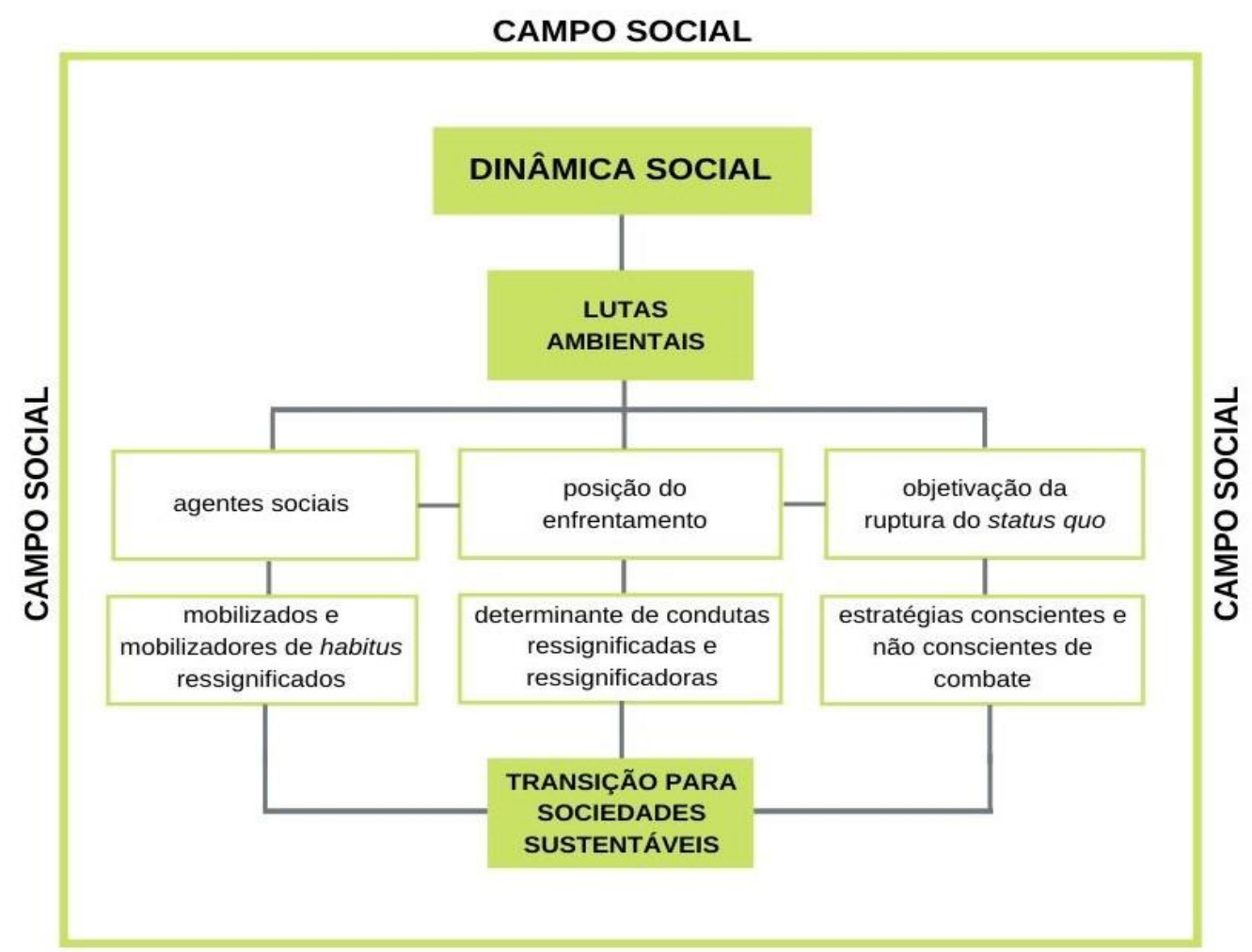

CAMPO SOCIAL

Figura 1: Atuação de educadores ambientais no processo de (re)construção de sociedades sustentáveis à luz da teoria bourdieusiana

Fonte: Elaboração própria à luz das obras de Bourdieu (1983, 2005), (2020). 
Todavia, para que esse processo transcenda a condição de constructo e se torne concretude, é preciso que nos reconheçamos educadores ambientais e que pautemos nossas ações em estratégias estabelecidas a partir da tomada de consciência da estruturação social da qual fazemos parte e do meio social do qual somos fruto, de modo que nossos discursos e nossas ações cheguem até os agentes que estão com a consciência alheia ao processo de modo entendível e mobilizador de transformações. E, ao falarmos em transformação, não nos referimos às ações pontuais relacionadas à educação ambiental que comumente estão a serviço das forças do capital, mas, sim, às ações capazes de arrefecer e solapar o modus vivendi e operandi, no qual se fundamenta o status quo.

Para tanto, é basilar que a atuação social seja concebida em uma dimensão ambiental e no questionamento dos fatores que estruturam o capital, as representações de mundo, os conflitos cotidianos, as estruturas cognitivas e os instrumentos reguladores da conduta humana, pois são esses os elementos que continuamente se reestruturam para a manutenção da ordem dominante. Com efeito, é, então, imprescindível a atuação dos educadores ambientais no processo de tomada de consciência para a mobilização coletiva por políticas públicas baseadas na sustentabilidade e na equidade para que as sociedades sustentáveis sejam uma realidade, visto que são elas o baluarte que possibilita a transformação do estruturalismo societário.

\section{Considerações finais}

Com base nas reflexões aqui elencadas, a crise emergente do cenário pandêmico não se iniciou no tempo presente nem cessará com o fim da pandemia, uma vez que é desdobramento de uma conjuntura que requer uma atuação social transformadora da estrutura social em uma perspectiva coletiva na qual os agentes sociais possam se reconhecer como educadores ambientais e, desse modo, (re)construtores de uma realidade ressignificada com base na sustentabilidade, reverberando, assim, em sociedades sustentáveis. Nesse sentido, a dimensão ambiental dos processos educativos e das ações humanas é um fator crucial e insurgente para o enfrentamento à pandemia, mas, para além dela, dos modos de ser e estar no e com o mundo arraigados em habitus consumistas e reprodutores da ordem dominante. A questão que fica é esta: estamos preparados para romper os grilhões que nos mantêm amarrados à perpetuação dessa situação? Ressignificar e transformar as lutas diárias não é fácil, sobremaneira frente às estratégias de cooptação e reinvenção do capital, mas não é impossível.

Dum spiro spero!13

${ }^{13}$ Enquanto respiro, tenho esperança!

Revbea, São Paulo, V. 15, № 4: 528-548, 2020. 


\section{Referências}

BOURDIEU, P. Questões de sociologia. Tradução: Jeni Vaitsman. Rio de Janeiro: Marco Zero, 1983.

BOURDIEU, P. Razões práticas: sobre a teoria da ação. Tradução: Mariza Correa. Campinas, SP: Papirus, 2005.

BRANDÃO, C. R. Comunidades aprendentes. Encontros e Caminhos: formação de educadoras(es) ambientais e coletivos educadores. Brasília: 2005. p. 83-91.

CAMPOS, D. B.; CAVALARI, R. M. F. O professor de Biologia enquanto educador ambiental: delineando o perfil de um caso particular de sujeito ecológico. Pesquisa em Educação Ambiental, v.12, n.1, p. 58-70, 2017.

CARVALHO, I. C. M. Educação ambiental: a formação do sujeito ecológico. 6 . ed. São Paulo: Cortez, 2012.

DIEGUES, A. C. Sociedades e comunidades sustentáveis. São Paulo: NUPAUB/USP, $2003 . \quad$ Disponível em: $<$ http://nupaub.fflch.usp.br/sites/nupaub.fflch.usp.br/files/color/comsust.pdf>.

Acesso em: 11 jun. 2020.

FREIRE, L.; FIGUEIREDO, J.; GUIMARÃES, M. O papel dos professores/ educadores ambientais e seus espaços de formação. Qual é a educação ambiental que nos emancipa?. Pesquisa em Educação Ambiental, v.11, n.2, p. 117-125, 2016.

GADOTTI, M. História das ideias pedagógicas. São Paulo: Ática, 2003.

GROPPO, L. A. A globalização e seus críticos. Ciências Sociais Unisinos, n.41, jan./abr., p. 37-42, 2005.

GUIMARÃES, M. Armadilha paradigmática na educação ambiental. In: LOUREIRO, C. F. B.; LAYRARGUES, P. P.; CASTRO, R. S. (Orgs.). Pensamento complexo, dialética e educação ambiental. 2. ed. São Paulo: Cortez, 2011. p. 11-29.

IASI, M. L. O fetichismo e as formas políticas: o Estado burguês na forma burlesca. Blog da Boitempo. 2019. Disponível em: $<$ https://blogdaboitempo.com.br/2019/02/14/o-fetichismo-e-as-formas-politicaso-estado-burgues-na-forma-burlesca/>. Acesso em: 08 jun. 2020.

LAYRARGUES, P. P. Éducation à l'environnement et anti-écologisme au Brésil: un modèle d'enseignement au service de la reproduction sociale. Droit et cultures, n.78, 2019. Disponível em: $<$ http://journals.openedition.org/droitcultures/5544>. Acesso em: 09 jun. 2020.

LAYRARGUES, P. P. Muito além da natureza: educação ambiental e reprodução social. In: LOUREIRO, C. F. B.; LAYRARGUES, P. P.; CASTRO, R. S. Pensamento complexo, dialética e educação ambiental. São Paulo: Cortez, 2011. p. 72-103. 
LEFF, E. Racionalidade Ambiental: a reprodução social da natureza. 2. ed. Rio de Janeiro: Civilização Brasileira, 2014.

MARX, K. Manuscritos econômico-filosóficos. São Paulo: Boitempo, 2006. MÉSZÁROS, I. Para além do capital: ruma a uma teoria da transição. São Paulo: Boitempo, 2011.

MORAES, R.; GALIAZZI, M. C. Análise textual discursiva. 2. ed. ljuí: Editora Unijuí, 2013.

RATTNER, H. Sustentabilidade: uma visão humanista. Ambiente \& Sociedade., Campinas, n.5, 1999. p. 233-240.

SILVA, M. G. Questão ambiental e desenvolvimento sustentável: um desafio ético-político ao serviço social. São Paulo: Cortez, 2010.

SORRENTINO, M.; NASCIMENTO, E. P. Universidade e Políticas Públicas de Educação ambiental. In: AZEVEDO, D. Educação em foco. Juiz de Fora: Editora UFJF, set. 2009/fev. 2010. p. 15-38.

TONET, I. Educação e Meio Ambiente. Rebela, v.3, n.5, 2015. p. 1-12. 